\title{
La Reforma en primera persona: Lutero y el problema de la libertad humana
}

Omar Jerónimo Prieto Ruiz'

Universidad Autónoma de Colombia

\section{Resumen}

Solemos asociar la obra de Martín Lutero con la Reforma Protestante, y esta, a su vez, con el inicio de la modernidad europea. Aunque existen distintos elementos que permiten el tránsito entre un fenómeno y otro, la relación no deja de ser problemática. El interés fundamental de Lutero es el problema de la salvación, que implica, para él, una crítica a la noción tradicional de libre albedrío. Se pretende mostrar las características del cambio teológico introducido por Lutero, y la estrecha relación de su obra con su personalidad. La modernidad, que se pretende secular, debe mucho a esa discusión religiosa.

Palabras Clave: pecado, salvación, libre albedrío, fe, justicia, Dios.

Filósofo y Magister en Filosofía de la Universidad Nacional de Colombia. Candidato a Doctor en Procesos Sociales y Políticos en América Latina, en la Universidad de Arte y Ciencias Sociales de Santiago de Chile. Docente de la Facultad de Ciencias Humanas de la Universidad Autónoma de Colombia. Correo electrónico: omarjprietor@gmail.com 


\title{
The Protestant Reformation in first person: Luther and the problem of human freedom
}

\begin{abstract}
We usually associate the work of Martin Luther with the Protestant Reformation, and this, in turn, with the beginning of European modernity. Although there are different elements that allow the transit between one phenomenon and another, the relationship is still problematic. Luther's fundamental interest is the problem of salvation, which implies, for him, a critique of the traditional notion of free will. It is intended to show the characteristics of the theological change introduced by Luther, and the close relationship of his work with his personality. Modernity, which is meant to be secular, owes much to this religious discussion.
\end{abstract}

Keywords: Sin, salvation, free will, faith, justice, God.

\section{A Reforma em primeira pessoa: Lutero e o problema da liberdade humana}

\section{Resumo}

Associa-se a obra de Martin Lutero com a Reforma Protestante e esta com o inicio da modernidade europeia. Embora existam elementos que permitem o trânsito entre um fenômeno e outro, a relação não deixa de ser problemática. $\bigcirc$ interesse fundamental de Lutero é a salvação, que implica uma crítica à noção tradicional de libre arbítrio. Este artigo pretende mostrar as características da mudança teológica introduzida por Lutero, mesmo como a relação estreita da obra e a personalidade dele. A modernidade, supostamente secular, esta na dívida com esta questão religiosa.

Palavras chave: pecado, salvação, fé, justiça, Deus, livre arbítrio.

\section{Introducción}

Es propio del método hermenéutico de las Ciencias Humanas tener en cuenta en el análisis de un determinado autor al menos tres niveles básicos de interpretación: primero, el autor mismo visto como persona humana, en donde se examinan sus influencias, su contexto histórico-social, su vida, sus propósitos, etc.; luego su obra, como consecuencia muchas veces de sus circunstancias vitales, y de sus intenciones y preocupaciones frente al horizonte conceptual en el que se educa; y, por último, las consecuencias o las diversas interpretaciones de las que ha sido objeto su obra. Estos tres momentos son puntos de referencia que permiten una visión mucho más completa para encarar el estudio de un personaje. En Martín Lutero vemos esos tres aspectos ligados de manera íntima, en particular los dos 
primeros. Nos interesa en estas páginas sustentar la idea de que Lutero, antes que ser considerado como reformador de la Iglesia, como el mentor de un gran cisma al interior de la misma, es, ante todo, un hombre constituido desde sí mismo, desde su propia experiencia. Que Lutero, antes que ser el gran reformador, es el gran reformado, el sujeto histórico fruto de un difícil proceso de maduración personal que lo lleva a la certeza de la incapacidad del hombre para disponer de su voluntad hacia el bien, de la negación de la libertad humana. En Lutero no son diferentes el hombre y la obra.

Por este solo hecho, se encontraba colaborando en una reforma religiosa tomada desde dentro y no desde fuera. Sin duda alguna no pensaba poner remedio a los abusos exteriores y formales de una iglesia; o, más bien, no pensaba en ello más que accesoriamente; era a sus ojos una tarea secundaria, que se cumpliría por sí misma cuando la meta estuviera alcanzada. Y la meta era transformar el corazón, las disposiciones íntimas, la actitud hacia Dios de los fieles privados de guía, o más bien extraviados por guías peligrosas².

En este orden de ideas, el conjunto de transformaciones sociales, culturales y políticas que conocemos con el nombre de "Reforma Protestante" es el efecto no intencionado del pensamiento de Lutero, resultado de diversas interpretaciones e intereses que tienen en la obra del monje agustino un punto de referencia sin que éste, por su parte, lo haya pretendido conscientemente. A diferencia de esa interpretación tradicional que convierte a Lutero en una suerte de revolucionario - o de hereje según el lugar desde donde se juzgue su empresa-, encontramos en él una preocupación fundamentalmente teológica que se resuelve en la interioridad de la conciencia del cristiano en su búsqueda de salvación, es decir, en el reencuentro con Dios que implica el reconocimiento de la naturaleza pecadora de la creatura. Antes que una transformación socio-política, o una "reingeniería" a la institución eclesial, el objetivo de Lutero, plasmado en sus obras, es alcanzar la gracia de Dios. El cambio, la reforma si se quiere, no se lleva a cabo en un nivel exclusivamente moral, sino en la búsqueda de un nuevo modo de ser humano, de un nuevo aspecto en la naturaleza humana sobre el cual quepa apoyar con firmeza y sin vacilaciones la presencia de la divinidad. Que esa búsqueda de un nuevo cimiento para establecer la relación con Dios haya sentado las bases para la configuración de la subjetividad moderna europea, es algo que solo se puede afirmar al analizar retrospectivamente la teología luterana en el contexto de transformaciones que permiten el cambio de época, pero no podemos confundir los efectos que se desprenden de ella con los propósitos de la misma. El aporte de Lutero, el cambió de significación al concepto tradicional de libre albedrío, es el núcleo fundamental de su doctrina, el motor, la raíz principal de todo su pensamiento teológico, y su mayor influencia - involuntaria - para el desarrollo posterior de la modernidad europea. Lo que nos interesa señalar en adelante es que ese cambio en el planteamiento del problema tiene como trasfondo necesario la persona de Lutero y su particular interés por resolver el dilema de la salvación del alma; que el desarrollo del pensamiento expuesto en la obra sólo aparece al configurarse la personalidad del autor.

2 FEBVRE, Lucien. Martín Lutero: un destino. México: Fondo de Cultura Económica, 1998, pág. 116. 
Para entender esto será necesario rastrear los tópicos fundamentales del proceso que recorre Lutero hacia el afianzamiento de su personalidad histórica, que coincide necesariamente con la tesis de la voluntad esclava y el posterior descubrimiento de la doctrina de la salvación por la fe. En la primera parte del texto intentaremos aproximarnos a los argumentos que expone Lutero para la negación del libre albedrío, y posteriormente nos acercaremos a la exposición de la doctrina de la justificación por la fe, aspecto fundamental, si bien paradójico, de su pensamiento, pues en un primer momento, como parte de su desarrollo individual, la libertad humana es tajantemente negada, y sólo al afianzarse, según la denominación de Manuel Ballestero, como sujeto trascendental, llega a afirmar la libertad del cristiano en el fuero interior de su conciencia, en el contacto de la criatura con el Creador por medio de la Fe.

\section{Un monje atormentado}

En un mundo semejante de cambio secular y espiritual e incertidumbre, fue en el que el joven graduado de veintidós años llegó a creer que la única vía abierta para él, para encontrar el sentido de la vida y entregarse a Dios, era hacerse monje. Contra la opinión de su padre, y después de un fuerte conflicto interior, Lutero volvió la espalda al mundo y a una prometedora carrera universitaria, para ofrecerse completa e incondicionalmente a Dios ${ }^{3}$.

A pesar de la influencia que su obra pueda tener en algunos aspectos centrales de la configuración del sujeto moderno europeo, Lutero es un hombre medieval orientado por las preocupaciones que se desprenden de su concepción del ser humano, y del lugar que le corresponde dentro del orden general de un mundo concebido como creación de Dios. Porque es esa particular relación con la divinidad, en el afán por encontrar los medios más adecuados para ser salvo, el motor principal de toda su vida. El problema de la salvación, es decir, la superación de esa distancia entre creador y creatura impuesta por el pecado original, es la preocupación fundamental de Lutero que nos permite entenderlo como un hombre medieval. Con el término "medieval" no me refiero a una cierta estructura sociopolítica y a su modelo económico predominante, sino a una mentalidad, a una forma de entender la realidad que tiene en el "trasmundo" el centro de referencia para la comprensión de todo lo existente. Para esa cosmovisión que tiene en una realidad trascendente su centro de referencia, la vida material no tiene sentido por ella misma sino en tanto paso previo y provisional hacia el más allá. Esa subvaloración de la experiencia terrenal en pos de la vida espiritual se traduce en una visión negativa del cuerpo humano y todas sus manifestaciones sensibles. Concebido como fuente de pecado y corrupción, como lo in-mundo, realidad material contraria a Dios, debe ser disciplinado, purificado y, en último término, superado. Por ello la experiencia del mundo material, que primero es corporal, está filtrada por la expectativa en ese más allá entendido como lugar de encuentro con

3 ATKINSON, James. Lutero y el nacimiento del Protestantismo. Madrid: Alianza Editorial, 197I, pág. 58. 
la divinidad, espacio de realización humana al que se puede acceder una vez se ha renunciado a las tentaciones que ofrece la vida terrenal. El mundo material, entendido como un "valle de lágrimas", no tiene valor por sí mismo; es más un lugar de tránsito que un objetivo final. Precisamente por lo anterior los intereses económicos o políticos deben subordinarse al problema de la salvación $n^{4}$. La idea de la apropiación material y la acumulación capitalista va en contra del esquema de vida trascendente que privilegia el alma sobre el cuerpo ${ }^{5}$; la vida espiritual interna es radicalmente diferente a la exterioridad del mundo.

Uno de los aspectos más llamativos de Lutero, y que permite su acceso al vasto público alemán, es el hecho de que fue educado dentro de un ambiente de superstición y misticismo. En su tiempo todavía se creía que el mundo tenía una órbita mágica, que estaba dominado por espíritus, la mayoría de ellos malignos. El diablo, las brujas, los duendes y demás seres malévolos eran parte del mundo con tal realidad y presencia como todo el universo del santoral cristiano. Esta "actitud premoderna ante la naturaleza", ese condicionamiento de categorías mentales medievales, no le permitía entender que ya se empezaba a vislumbrar en el horizonte una nueva forma de comprender la naturaleza, una nueva cosmología racional que explicaba el mundo con base en relaciones causales ${ }^{6}$. Tal como lo explica Jean Delumeau en su interesante estudio sobre "El miedo en Occidente", el contexto de la vida de Lutero se encuentra impregnado por una diversidad de manifestaciones de lo demoníaco que, sumadas a las ideaciones milenaristas y a la muerte que acecha por doquier en distintas formas - peste, tuberculosis, sífilis, difteria, etc. — creaban un clima espiritual y psicológico propicio para la aceptación de la objetividad del mal. Los judíos, la peste, los turcos, las mujeres vistas como los "agentes de Satán", son algunas de las manifestaciones que atemorizan a los seres humanos, y que al mismo tiempo que los llenan de angustia, los arrojan a los brazos protectores de la institución eclesial, intermediaria natural entre Dios y sus atormentadas creaturas. El pecado es real en el mundo, al igual que el mal, y el convivir con él día a día es lo que lleva a la conciencia de las personas a pensar en la urgencia de la salvación, y a configurar también una serie de ritos - sacrificios, reliquias, sacramentos, pago de indulgencias - intrincados y extensos, para contrarrestar el mal que los asedia. Como lo explica Ricardo García-Villoslada:

[...] toda la tierra estaba poblada de espíritus malignos sin otra ocupación que la de hacer daño a los hombres mortales. Los demonios más altos y sutiles habitan en el fuego y en el aire, por debajo de la luna; los ígneos no tienen comercio con los hombres; los aéreos provocan perturbaciones atmosféricas; otros tienen su morada en los bosques y son los que extravían a los viajeros. Por eso los mineros tenían tanto miedo a los espíritus infernales, y el padre de Lutero, que trabajaba en las

4 TROELTSCH, Ernst. El protestantismo y el mundo moderno. México: Fondo de Cultura Económica, 2005

5 La usura, uno de las actividades principales del naciente modo de acumulación capitalista, era considerada, desde todo punto de vista, como un pecado, como una afrenta hacia Dios. Cfr. "Sobre el comercio y la usura" del año I 524.

6 JARAMILLO VÉLEZ, Rubén. La actitud premoderna y moderna ante la naturaleza. En: Argumentos, número 30. Bogotá: Editorial Argumentos, 1993, págs.33 - 43. 
minas de Eisleben y de Mansfeld, lo transmitió a su hijo Martín, en quien la obsesión del diablo fue continua?.

En este contexto en el que crece Lutero, y que constituyó el ámbito dentro del cual realizó su vida monacal, la actividad humana, mediada por su voluntad, implicaba que cuando la persona quebrantaba una norma establecida o era presa de sus pasiones humanas más básicas, debía confesarse, ofrecer a Dios un sacrificio, ejecutar una obra de carácter simbólico que expiara su culpa; se pretendía que con ese acto, como consecuencia del reconocimiento de su falta ante el confesor, se libraba del castigo que vendría de Dios. En esta concepción del pecado y la condenación, que es la base de la angustia del joven Lutero, cuando el hombre pecaba, ese acto destruía su relación con Dios alejándolo de él. Para restaurar la relación, para volver a Dios, era menester un acto de arrepentimiento y de penitencia que fuera lo suficientemente bien intencionado como para merecer su perdón, para componer diplomáticamente la relación. Para alcanzar la gracia de Dios o, si se quiere, para "agradarlo", la Iglesia católica postulaba que era necesario, imperiosamente, que el hombre se hiciera justo, promoviendo una relación con Dios por medio de un cuerpo doctrinal ritual. Si bien la justificación es obra de Dios, lo que él hace es premiar, coronar los méritos adquiridos por un esfuerzo moral de la voluntad, haciendo desaparecer el pecado y enalteciendo el papel de la moral humana. El problema fundamental de la salvación era resuelto por medio de la aceptación de la libertad del hombre.

Esta idea de la salvación estaba sustentada en la concepción tradicional del libre albedrío, concepto problemático que supone que la voluntad humana, a diferencia del entendimiento, es infinita, absoluta. El libre albedrío, entendido como la capacidad de la voluntad para obrar con total autonomía en el momento de elegir entre el bien y el mal y, por lo tanto, de su capacidad para elegir el mal, planteaba serios problemas al momento de explicar el pecado, el mal moral, pues, como ya "los escolásticos lo habían expresado con su lenguaje claro: ¿cómo es posible que la voluntad humana desee el mal, cuando el mal es por su misma naturaleza algo indeseable?"'. La noción de libre albedrío, amparada en la separación entre entendimiento y voluntad, es un desafío tanto para la filosofía como para la teología, pues plantea problemas complejos relacionados con esa pretendida capacidad de la voluntad para obrar incluso en contra de los dictados de la razón. Se puede entender la dificultad que comporta asumir que parte de lo que implica definir la voluntad como infinita tiene que ver con la posibilidad de trasgredir los límites de la razón, de actuar al margen o en contra del intelecto, lo que nos lleva a la posibilidad de aceptar acciones racionalmente injustificables?.

Lutero se formó dentro de esta concepción que admitía la capacidad del ser humano para optar por su salvación por medio de la libertad de su voluntad. El planteamiento ofrecido suponía en el ser humano la capacidad para elegir entre muchas opciones diferentes la que fuera más conveniente

7 GARCÍA-VILLOSLADA, Ricardo. Raíces Históricas del Luteranismo. Madrid: Biblioteca de Autores Cristianos (BAC), Segunda Edición, 1976, pág. 222.

8 DIAZ, Jorge Aurelio ¿Existe el mal moral? En: URIBE BOTERO, Ángela y De GAMBOA TAPIAS, Camila (editoras). Fuentes del mal. Bogotá: Universidad Nacional de Colombia, Universidad del Rosario, 2012, pág. 20.

9 Ibídem. pág. 21. 
para su beneficio y, por lo tanto, frente al problema de la salvación estaba en la capacidad para elegir el bien. Hasta este punto no parece haber inconvenientes en la definición, pero para Lutero, sin embargo, es esa misma aceptación de la capacidad del hombre lo que va a ir en contra de su doctrina y lo que merecerá mayor énfasis y atención. Esta idea de la libertad como la capacidad de la voluntad para actuar de manera por completo autónoma, no sólo iba a contradecir el núcleo fundamental de su pensamiento sino que iba a presentar un problema mayor al momento de afrontar el asunto de la salvación pues, si bien era perfectamente comprensible el hecho de que la voluntad optara por el bien, no se veían razones explicativas suficientes para dar cuenta del libre albedrío cuando está referido al mal. No existía una explicación consistente del por qué puede el hombre obrar mal a conciencia; de por qué actúa mal.

Lo que daba estabilidad a la concepción de la Iglesia era la creencia de que la naturaleza humana, a pesar del pecado original, no había perdido todo contacto con la realidad espiritual y por lo tanto era posible trazar un puente, desde la institución temporal, entre el hombre y Dios; que era posible explicar el pecado desde la voluntad del hombre. Para Lutero, por el contrario, la distancia entre el hombre y Dios es infinita y no puede solventarse desde el mundo, sino por el propio Dios. La crítica que Lutero hace de la Iglesia en cuanto institución, y que lo lleva a desvalorizar la práctica exterior como mediación innecesaria, no es porque la organización institucional sea negativa por sus abusos o prácticas incoherentes a todo nivel, sino porque es de carácter mundano, exterior; porque basa toda su confianza en la capacidad del hombre para alcanzar por sí mismo la salvación depositando la solución al problema en el ámbito de los actos humanos, dejando de lado la acción y el poder de Dios en su criatura.

Esta confianza en la capacidad del ser humano para alcanzar por sí mismo la salvación es la que configura la doctrina de las obras que, como ya se ha mencionado, consiste en una determinada concepción del pecado que no implica la separación radical entre Dios y el hombre ya que, definido como una acción moral, puede compensarse también moralmente a través de una amplia oferta de acciones y rituales que la iglesia católica consideraba "buenas" y necesarias. En su periodo monástico Lutero todavía está convencido que a través de las obras es posible superar el mal que lo atormenta. Experimenta rigurosamente todas las alternativas que le ofrece la vida en el convento, convencido, a pesar de su frustración, de recorrer el camino seguro hacia la eternidad. Pasados los años recuerda que

[...] Cuando fraile era también muy piadoso en mis tiempos papistas; a pesar de todo, me encontraba tan triste y acongojado, que llegué a pensar que Dios me había retirado su gracia. Decía misa y rezaba; no veía entonces ni tenía a mujer alguna, cosa natural al ser fraile y pertenecer a una orden religiosa. Ahora, el diablo me fustiga con otros pensamientos. Muchas veces me recrimina: «A cuántas personas has seducido con tu doctrina». En ocasiones hallo consuelo, pero en otras circunstancias cualquier palabra basta para conturbar mi corazón. Una vez me dijo mi confesor, puesto que siempre acudía a él con pecados estultos: «Eres un necio; Dios no se enfada contigo, eres tú quien está enfadado con él; no está enojado 
contigo, sino tú con él». Palabras preciosas, grandes, estupendas, que pronunció iluminado por el evangelio ${ }^{10}$.

Como lo explican distintos comentaristas, Lutero asume una estricta vida en el convento convencido que esa serie de acciones y sacrificios son el método adecuado para alcanzar la salvación. Ese entramado de ritos, oraciones y prácticas ascéticas se sustentaban en la idea de que el hombre puede, en virtud de la libertad de su voluntad, elegir el bien, es decir, actuar de tal manera que pueda llegar a merecer el perdón de sus pecados. Sin embargo, "El experimento, para Lutero, no era sino demasiado probatorio: la vida monástica no bastaba para darle la paz; las prácticas, los ayunos, las salmodias en la capilla, los rezos prescritos y las meditaciones, remedios buenos para otros, que no tenían una sed tal de absoluto"'।. La experiencia de la vida monacal, ese tiempo en el que asume radicalmente la idea de que la salvación se alcanza en un proceso permanente de acciones bien intencionadas, no resuelve el problema del pecado que atormenta a Lutero. Se esfuerza permanentemente por actuar bien, por seguir los mandatos de la iglesia y cumplir los sacramentos, pero sigue sintiendo que el objetivo rebasa tanto sus métodos como sus posibilidades. El pecado no desaparece, y el camino escogido parece llevarlo siempre al punto inicial. ¿Cómo superar entonces esta encrucijada?

\section{Sola Fide}

Es posible descubrir los primeros indicios de la doctrina luterana de la justificación en el "Comentario a la Carta a los Romanos" de 1522, aunque el texto del que disponemos no proviene de la pluma del mismo Lutero, sino de los apuntes tomados por uno de sus discípulos, y sólo vino a publicarse a principios del siglo XIX. La tesis, que será fundamental para todo su pensamiento, sostiene que la "justicia de Dios", es decir, la salvación, es imputada o adjudicada al hombre, que es pecador por naturaleza, por una acción de Dios. El término "justicia de Dios" (dikaiosyne tou Theou) es el punto central, ya que es interpretada por Lutero como la justicia que Dios le otorga al hombre sin tener en cuenta mérito alguno de su parte. Para ello se apoya en el sentido general de la carta de San Pablo, cuya doctrina se orienta en la misma dirección. Esta nueva visión permite al hombre buscar a Dios en su palabra y acceder a su justicia al admitir su naturaleza esencial al comprender, o mejor, al aceptar conscientemente que por medio de la obediencia de Cristo la ley ha sido cumplida "en pro de él y no por él". Esta es otra forma de decir que la fe supera todos los esfuerzos puestos en las obras humanas.

Para explicar lo anterior conviene precisar algunos términos fundamentales según el sentido que Lutero le otorga a los mismos, apoyados en la interpretación de la "Palabra de Dios" que hace en dicha obra.

10 LUTERO, Martin. Obras. Edición de Teófanes Egido. Salamanca: Ediciones Sígueme. 1977. pág. 429. La referencia corresponde al conjunto de relatos conocidos con el nombre de "Charlas de sobremesa", compilación testimonial elaborada por distintos discípulos de Lutero tras conversar con él, como su nombre lo indica, después de comer.

II FEBVRE, Lucien. Martín Lutero: un destino. México: Fondo de Cultura Económica, 1998, pág. 47. 
La palabrita ley no debe entenderse en sentido humano, es decir, como enseñanza de las obras que hay que hacer y las que hay que evitar, lo que es propio de leyes humanas, que se cumplen con obras, aunque el corazón no sea partícipe. Dios juzga lo íntimo del corazón. Por eso, su ley se dirige a lo más íntimo del corazón, y no se satisface con obras; por el contrario, censura las que no proceden de un corazón sincero, como hipocresías y mentiras ${ }^{12}$.

Es vital esclarecer el concepto de ley para comprender la innovación teológica que se gesta. La concepción católica de la justificación opera sobre un concepto de ley que privilegia la acción humana en el sentido de que su cumplimiento, por una decisión libre de la voluntad, justifica al hombre de sus pecados. Es cierto que la salvación es obra de Dios pero el ser humano, con su voluntad, colabora en la misma. Para Lutero, en cambio, la acción del hombre no tiene nada que ver con su salvación, ya que ésta es un don gratuito que, teniendo en cuenta el sacrificio de Jesús, le es otorgado al hombre por pura gracia. Oigamos de nuevo a Lutero:

[...] cualquiera encuentra en sí mismo desgano para realizar el bien y placer para realizar el mal. Cuando no existe el libre placer de hacer el bien, tampoco existe esa íntima armonía del corazón con la ley de Dios; entonces ciertamente también hay pecado e ira merecida de Dios, aunque exteriormente aparezcan muchas obras buenas y una vida honrada!3.

La función de la ley es afirmar la incapacidad del hombre de ser fiel a ella por sí mismo, llevándolo a la aceptación casi trágica de su naturaleza pecadora. Pero esa misma aceptación de su condición de impotencia viene a ser el terreno fértil para el advenimiento de la gracia. Cuando el hombre reconoce que no es malo porque obre mal, porque quebrante la ley que Dios mismo ha impuesto sino que, más bien, obra mal porque tiene una naturaleza mala, siente entonces un profundo vacío, una verdadera angustia; pero eso mismo constituye su preparación para alcanzar una nueva conciencia de sí, una "conciencia triunfante" como la llama Paul Tillich, por medio de la cual es elevado desde sí mismo hacia Dios.

Si de este modo la conciencia mala entra en un estado de absoluta desesperación, puede ser vencida sólo por la aceptación del amor sacrificado de Dios, como se puede percibir en la imagen de Jesús como Cristo. Dios mismo ha decidido asumir, en su Hijo, las consecuencias del pecado, cargando Él con la responsabilidad y reestableciendo de esta manera la comunión con el hombre. El pecador es aceptado como tal pese a su naturaleza pecaminosa. La ira de Dios ya no nos atemoriza; una conciencia alegre nace y se eleva «por encima» de la esfera moral, tanto como

12 LUTERO, Martín. Comentario a la carta a los Romanos. Volumen I. Traducción de Erich Sexauer. Barcelona: Editorial CLIE, I998, pág. 13.

13 Ibídem. 
aquella conciencia desesperada se encontraba «por debajo» de esa misma esfera moral't

De esta manera interpreta Lutero el concepto de ley como una entidad espiritual de origen divino, ya que, si se tratara de una convención humana, el problema de la salvación se resolvería mediante las obras. Compromete por lo tanto la interioridad del hombre, su corazón, de modo que por la acción de la gracia Dios lo hace concordar con su voluntad, sintiendo agrado en su cumplimiento y no sólo el peso de una obligación. Como una cosa es realizar las obras de la ley y otra cosa muy distinta cumplir la ley, nos dice Lutero, por mucho que se esfuerce el hombre en realizar buenas obras, seguirá atado al pecado porque, como dice Pablo, "ningún hombre será justificado ante Dios mediante las obras de la ley". Dios y su salvación son dados al hombre sólo en, con o por la fe en Jesús, de acuerdo con la Palabra de Dios. "De aquí proviene que solamente la fe justifique y cumpla la ley, pues obtiene el espíritu por el merecimiento de Cristo, espíritu que hace al corazón alegre y libre como lo exige la ley"'15.

Es importante profundizar también en el concepto de pecado, pues se supone que es éste quien mantiene la voluntad esclava, incapaz de realizar el bien: "La Sagrada Escritura llama pecado, no solamente a la obra exterior del cuerpo, sino a todas las actividades que impulsan o mueven hacia ella, es decir, lo íntimo del corazón con todas sus fuerzas [...] Pues no se produce ninguna obra exterior del pecado a menos que el hombre se empeñe en ella con cuerpo y alma"'6. La concepción luterana del pecado, más allá de reproducir el viejo concepto y el viejo dilema por su relación con la Ley, lo ubica en un plano ontológico, no en un plano ético, acrecentando por ello su distancia con la Iglesia Católica. Los hombres no hacen cosas malas, son malos por culpa del pecado. "Así como solamente la fe justifica, trayendo consigo el espíritu y el placer para las buenas obras exteriores, de la misma manera también solamente la incredulidad peca e incita a la carne y la hace complacerse por las malas obras exteriores" 17 . El pecado, como tal, introduce la muerte en la realidad humana; el hombre es su esclavo y por ello no puede tener control de sus propias acciones que son todas malas por definición. Esta condición pecaminosa crea un distanciamiento con Dios que solo puede ser remediada por Dios mismo. Así, como dice el apóstol, "Ya no soy yo el que hace eso, sino el pecado que habita en mî" (Romanos, 7, 17-20). Por lo tanto, como estructura formal tiene su propia ley, y el hombre es prisionero de ella.

Lutero está convencido de la naturaleza formal del mal y de su existencia en el mundo, hemos dicho ya. A ello hace referencia casi en todos sus textos, y lo considera como lo demoníaco, como

14 TILLICH, Paul. La Era Protestante. Buenos Aires: Editorial Paidós, 1965, pág. 224.

I5 LUTERO, Martín. Comentario a la carta a los Romanos. Volumen I. Traducción de Erich Sexauer. Barcelona: Editorial CLIE, I998, pág. 16.

16 Ibídem.

17 Ibídem. 
la presencia objetiva del mal en el mundo manifestado en el pecado. "La idea de lo demoníaco es la expresión mítica de una realidad que formaba la verdadera médula de la experiencia de Lutero, y también de la de Pablo, es decir, el poder estructural (Gestalt) y por tanto ineludible del mal"18. No se toma aquí el término "demoníaco" en su uso supersticioso y abominable tan típico de la Edad Media y tan criticado por los humanistas, sino como expresión de una realidad ontológica, tal como lo pensaba Lutero en contravía de Erasmo de Rotterdam, quien veía el mal como resultado de la libre decisión de una persona consciente de sus actos, atendiendo sólo a los actos individuales del mal. Lo demoníaco es para Lutero, como lo explica Tillich, un problema que rebasa los límites de lo ético y lo moral, ubicándose en el plano de lo metafísico existencial, razón suficiente para entender su profunda y desgarradora angustia en pos de la salvación ${ }^{19}$, y vista como la luz esperanzadora de una personalidad anhelante de consuelo que tiene que atravesar sin embargo un largo túnel de oscuridad. Esta experiencia, acentuada por su concepción del mal como una Gestalt, como figura que va más allá del poder moral de la voluntad, se convierte en una tragedia, pues al funcionar como estructura, en su sentido demoníaco, limita la libertad del individuo. El pecado no es, entonces, una simple flaqueza que se pueda remediar por medios externos, sino un poder maldito, infinito, invencible, que separa al hombre de su Creador. Es una existencia única, privación de toda rectitud y de toda eficacia de las facultades humanas, tanto del hombre exterior (cuerpo) como del hombre interior (alma). En el hombre no hay mal en el sentido ético de transgredir, de traspasar conscientemente un límite; no es un acto negativo sino algo más grave: un vacío, una carencia de ser.

En las "Charlas de sobremesa", Lutero hace una analogía para referirse claramente a lo que entiende por pecado, al decir que es igual a la barba en el hombre que, a pesar de que se afeite a diario, siempre vuelve a aparecer de manera incesante durante toda la vida, acabando sólo con la muerte. De la misma manera permanece y actúa el pecado original a lo largo de la existencia humana, según la concepción de nuestro autor. En los "Artículos de Schmalkalda" Lutero vuelve sobre este tema diciendo:

Tenemos que confesar aquí que, como dice Pablo (Romanos 5), el pecado entró en el mundo por un solo hombre, Adán, por cuya desobediencia todos los hombres se convirtieron en pecadores y fueron sometidos a la muerte y al diablo (Romanos 5, 12). Esto es lo que se llama pecado original o capital. Los frutos de este pecado son las obras malas proscritas en el Decálogo. Este pecado original entraña una corrupción tan profunda y perniciosa de la naturaleza, que ninguna razón llegará a comprenderlo. Por esta causa, no es más que error y ceguedad lo que los escolásticos han enseñado acerca de este artículo, es decir: las facultades naturales del hombre quedaron íntegras e incorruptas, y que el hombre, por natu-

I8 TILLICH, Paul. La Era Protestante. Buenos Aires: Editorial Paidós, 1965, pág. 23.

19 Esa experiencia de angustia y temor permanente, la obsesión por la presencia del demonio, acompañada de una culpa constante que lo llevaba a atentar contra su propia integridad física, es descrita desde un punto de vista psicoanalítico como una aguda neurosis. Al respecto es muy interesante el trabajo de Erick Ericsson, "Young Man Luther". 
raleza, goza de recta razón y de una voluntad buena, como enseñan los filósofos; que el hombre goza de libre albedrío para hacer el bien y abstenerse del mal y, viceversa, para abstenerse del bien y obrar el mal, que si el hombre hace cuanto de él depende, es seguro que Dios le dará su gracia. Que no se funda en la Escritura la necesidad del Espíritu Santo con su gracia para realizar una obra buena. Estas tesis y otras parecidas nacen del desconocimiento y de la incomprensión del pecado y de Cristo, nuestro salvador. Es una doctrina del todo pagana, imposible de ser tolerada por nosotros: porque si esta doctrina tuviese que ser la verdadera, entonces Cristo habría muerto inútilmente, puesto que el hombre no habría recibido daño, no tendría pecado alguno por los que hubiera tenido que morir. $\bigcirc$ hubiera muerto sólo por el cuerpo, no por el alma, ya que el alma está sana y sólo el cuerpo está destinado a la muerte ${ }^{20}$.

Este argumento, netamente teológico, acentúa la tesis de Lutero que niega la libertad humana, al señalar una vez más la incapacidad absoluta del ser humano para obrar el bien por sí mismo, pues sólo está en capacidad de obrar el mal. Esta concepción, por supuesto, va a sentar las bases del principio protestante de la justificación por la fe, pues esa misma visión del mal, esa dimensión metafísica generará también y con mayor fuerza la aceptación de su contrario: la gracia de Dios que justifica al hombre sólo por su relación de dependencia con él. Sólo la gracia justifica y salva al hombre de la realidad natural del pecado. La gracia de Dios como tal no es un adjetivo, sino un sustantivo: la forma de ser del Creador al entrar en contacto con su creatura. La gracia le sobreviene al hombre, no es creación subjetiva, actividad humana sino divina; es por lo tanto objetiva y el hombre sólo puede recibirla pasivamente. Decir que Dios le concede la gracia al hombre y éste está pleno de ella, es otra manera de decir que el hombre tiene fe. "La gracia crea la fe en virtud de la cual se la recibe", nos dice Tillich al respecto.

La concepción luterana del pecado, parte esencial de la naturaleza humana en tanto cosa creada, recibe la influencia de la concepción agustiniana en su disputa contra los Pelagianos, según la cual por el error de Adán el pecado pasa a los hombres por "propagación", como por contagio, no por imitación, pues, si fuera así, el hombre nacería inocente, sin pecado original y sin la necesidad de la redención. Pensaba San Agustín que si el hombre fuera pecador por imitación, el primer autor no sería Adán, sino el demonio a quien ha imitado; una cosa es la fuerza del ejemplo para los que pecan por voluntad propia, y otra la consecuencia original para los que nacen con pecado. Tal como dice Pablo: "Por un hombre entró el pecado en el mundo y por el pecado la muerte y así a todos los hombres alcanzó la muerte pues en él todos pecaron". Con respecto a esto Lutero afirma que "[...] antes que ocurran buenas o malas obras, como sucede en los buenos o malos frutos, debe existir primero en el corazón la fe o la incredulidad, como raíz, como sabia y fuerza principal de todos los pecados"2l.

20 LUTERO, Martin. Obras. Edición de Teófanes Egido. Salamanca: Ediciones Sígueme. 1977, págs. 344-345.

21 LUTERO, Martín. Comentario a la carta a los Romanos. Volumen I. Traducción de Erich Sexauer. Barcelona: Editorial CLIE, I998, pág. 17. 
Si un árbol está dañado desde su raíz, no podrá dar buenos frutos, nos dice metafóricamente. De allí la necesidad de la gracia. De allí su distancia profunda e insalvable frente a Erasmo, a quien acusa de semipelagianismo, pues defiende acérrimamente el libre albedrío como parte de una naturaleza humana guiada por la razón.

Para el humanista el hombre es fundamentalmente bueno; su quehacer radica en desarrollar su naturaleza por medio del mayor bien del hombre que es la libertad. Bajo su concepción el libre albedrío es la causa del pecado, pues peca el hombre "porque quiere", y por la misma razón es la causa de que no exista el pecado, pues, si no quiere, no peca. El pecado es un problema ético, de la acción y la voluntad humanas; un hecho que no puede existir sin un acto volitivo. Este humanismo de Erasmo, esa preocupación por incorporar al cristianismo el redescubrimiento de los clásicos basada en una confianza plena en la naturaleza humana, es lo que más lo separa de Lutero pues, si bien ambos son radicalmente antropocéntricos, la concepción de este último va en otra vía: la de la desconfianza absoluta en el hombre y su razón — negación que es la base para la afirmación de la interioridad y el surgimiento del sujeto moderno-. Para Lutero el hombre es fundamentalmente perverso, corrompido intrínseca y esencialmente por el pecado original. Todos sus actos, incluso los naturalmente honestos, son pecaminosos; el hombre está esclavizado bajo el dominio de la carne y su salvación será absolutamente pasiva, pues su voluntad es tan impotente para obrar el bien, que ni siquiera puede colaborar en su salvación. La distancia entre Erasmo y Lutero radica entonces en que en el primero lo humano, por decirlo así, prevalece sobre lo divino — de aquí la acusación de semipelagianismo - y en el segundo lo divino exige la aniquilación de lo humano; mientras que Erasmo tiene un optimismo radical por la naturaleza humana, Lutero la describe, y la valora, solo en su relación de dependencia con Dios ${ }^{22}$. Aunque presentado de una manera muy sucinta, este es en lo fundamental el debate entre Lutero y Erasmo en torno al libre albedrío ${ }^{23}$.

Precisamente en la desconfianza de Lutero por la capacidad del hombre para la salvación radica la importancia de la gracia y la fe, de la acción salvífica del Creador en su obra. Al respecto nos dice que "la diferencia entre gracia y dádiva es que gracia significa propiamente benevolencia o favor de Dios que él abriga consigo mismo hacia nosotros y que le inclina a darnos a Cristo, al espíritu con sus dones"24. Es tal la naturaleza de la gracia que es presencia permanente de Dios en el creyente, muy a pesar de su naturaleza corrupta que no puede ser modificada: "La gracia hace tanto que nos podemos considerar completamente justificados ante Dios; ella no se divide ni se fracciona, como ocurre con los dones, sino que nos incorpora totalmente en su benevolencia, por

22 MARTINEZ, Humberto. Lutero Vs. Erasmo: los orígenes de la secularización. México: Universidad Autónoma Metropolitana, 1985.

23 A pesar de ser considerados enemigos históricos, enfrentados por posiciones irreconciliables, estos dos personajes tuvieron una relación respetuosa y cercana hasta 1525, y compartieron más de un escenario: ambos son exalumnos de los Hermanos de la Vida Común, profesan una espiritualidad inspirada en Tomás de Kempis, ambos son monjes agustinos y se preocupan por difundir la Biblia entre el pueblo; incluso ambos tienen como enemigos a los teólogos y a los dominicos.

24 LUTERO, Martín. Comentario a la carta a los Romanos. Volumen I. Traducción de Erich Sexauer. Barcelona: Editorial CLIE, I998, pág. 18. 
causa de Cristo, nuestro intercesor y mediador y por haber comenzado los dones en nosotros"25. Y más adelante refuerza el poder de la gracia, al decir que "[...] somos todavía pecadores, por causa de la carne que todavía no ha muerto, pero porque creemos en Cristo y tenemos el principio del espíritu, Dios es tan favorable y misericordioso para con nosotros, que no considerará tales pecados, ni quiere juzgarlos, sino que procederá con nosotros según nuestra fe en Cristo, hasta que el pecado sea suprimido"26.

Por esta razón cobra vital importancia el asunto de la fe, piedra angular de la tesis protestante de la justificación, elemento básico de la doctrina. Ésta, comprendida como fiducial, como un acto de confianza absoluta en la palabra redentora de Dios, es un "don para creer", una aceptación del Infinito obrando en lo finito sin necesidad de razones, sacrificando la racionalidad en pos de una actitud meramente humano-cristiana; aceptando algo, aun cuando no haya razones para hacerlo. Lutero no se detiene a pensar en las implicaciones que pueda traerle tal concepción. Es, por encima de todo, un teólogo profundamente comprometido con su causa, convencido de ser elegido por Dios para descubrir a los hombres el verdadero sentido de ser cristiano, tan dilatado y oscuro en sus tiempos por la corrupción que encuentra en Roma. Por ello está seguro de que su obra es sagrada; de que es, como dice Lucien Febvre en su hermoso libro, "un destino", lo que significa para él un compromiso vital de hondas repercusiones que no está dispuesto a abandonar, aunque le implique graves consecuencias. Su obra secundaria, la nueva teología, es consecuencia de sí mismo. No es una revolución del estamento cristiano en la tierra, sino una transformación y una respuesta a su propio espíritu en combate: "Yo, a Dios gracias, tengo la convicción de que mi doctrina responde a la palabra divina, y he arrojado de mi corazón cualquier otra creencia, llámese como se llame. He vencido casi del todo los pensamientos y tentaciones con los que se acongojaba mi interior cuando me decía: «¿Es que vas a ser tú el único en detentar la palabra verdadera? ¿No la poseen también los demás?» ${ }^{27}$.

Esta posición radical, que no admite términos medios, es expresada a Erasmo cuando este le advierte de los peligros que puede traerle:

Tú das a entender que esta paz y tranquilidad de la carne te parece mucho más estimable que la fe, que la conciencia, que la salvación, que la palabra de Dios, que la gloria de Cristo, que Dios mismo. Por lo tanto yo te digo - y te ruego que prestes suma atención a esto-, que yo en esta lucha intento una cosa que para mí es seria, necesaria y eterna, que es de tal calibre que es necesario que seas afirmada y defendida incluso por medio de la muerte, también, aunque el mundo entero debiera arder en tumultos y guerras, más aun, aunque el mundo se precipitase en el caos y fuese reducido a cenizas. Si tú no entiendes esto, o no te atrae, dedícate

\footnotetext{
25 lbídem.

26 lbídem.

27 LUTERO, Martin. Obras. Edición de Teófanes Egido. Salamanca: Ediciones Sígueme. 1977, pág. 432. La referencia corresponde a las "Charlas de sobremesa".
} 
a tus asuntos y deja que aquellos a quienes Dios se lo ha «inspirado», lo entiendan y se dediquen a ello ${ }^{28}$.

Con esa misma pasión que lo llevó a no retractarse ante Carlos $\vee$ en la famosa escena de la dieta de Worms en 1522, defiende sus tesis, su concepción y su convicción de la fe, que va más allá de críticas racionales. Es clara en Lutero la dualidad irreconciliable entre fe y razón, como muchas otras a lo largo de su obra. Nada tiene que decir la filosofía en la reflexión teológica. Su punto de vista es religioso, es una actitud de vida donde lo racional carece de importancia. La teología pertenece a un ámbito de lo humano completamente diferente al ámbito filosófico defendido por Erasmo. Ese desprecio hacia la razón humana, que se manifiesta en el rechazo a la filosofía, le hace obviar las críticas sobre la incoherencia interna de su teología. Esto no le preocupaba en lo más mínimo al afirmar su doctrina de la fe, que implica la aceptación de una proposición como verdadera aun cuando existan razones para no hacerlo. Al respecto afirma Paul Tillich: "La filosofía y la teología son divergentes y convergentes. Convergentes, en tanto ambas son existenciales y teoréticas al mismo tiempo. Divergentes, por cuanto la filosofía es básicamente teorética y la teología es fundamentalmente existencial. Esta es la razón por la cual la filosofía puede descuidar sus fundamentos existenciales y tratar con el ser y los seres como si ellos no le concernieran en absoluto" 29.

Sentados estos precedentes, Lutero da su definición en varios apartes de su comentario a la Carta a los Romanos, donde afirma que la fe es "[... ] una viva e inconmovible seguridad en la gracia de Dios, tan cierta que un hombre moriría mil veces por ella. Y tal seguridad y conocimiento de la gracia divina hace al hombre alegre, valiente y contento frente a Dios y a todas las creaturas, que es lo que realiza el Espíritu Santo en la fe" ${ }^{\prime 30}$. Esta es entonces la puerta de entrada a la tan esperada justificación, y es el tesoro más preciado que debe buscar un cristiano: “[ ... r ruega a Dios para que produzca en ti la fe, de lo contrario quedarás eternamente privado de ella aunque inventes o hagas lo que quieras o puedas"3!.

Como se acaba de ver, el centro de la fe cristiana es que el hombre no puede nunca llegar a ganar o a merecer el favor de Dios, ni es lo que Dios espera de él. Todo depende de su gracia. Lo único que el ser humano puede hacer es aceptar y recibir con amor, gratitud y confianza la acción de Dios. El concepto de fe, centro de la teología paulina y luterana, está completamente cargado de sentido y es el motor inspirador para los dos. En un sentido amplio, la palabra fe significa lealtad, paciencia y firmeza, la fidelidad a toda prueba. Quiere decir también creencia, la convicción de que algo es verdad y, en el caso particular de Lutero, se interpreta como la aceptación de la verdad del evangelio, y también como una esperanza indestructible, pero en su sentido más puro quiere decir aceptación

\footnotetext{
28 LUTERO, Martín. De Servo Arbitrio. Traducción de Erich Sexauer. Buenos Aires: Editorial Concordia, 2006, pág. 67.

29 TILLICH, Paul. La Era Protestante. Buenos Aires: Editorial Paidós, 1965, pág. 152.

30 LUTERO, Martín. Comentario a la carta a los Romanos. Volumen I. Traducción de Erich Sexauer. Barcelona: Editorial CLIE, I998, pág. 19. Énfasis añadido.

3। Ibídem.
} 
total y confianza absoluta: fiducia ${ }^{32}$. Este es el sentido decisivo, aquel que permite la absoluta afirmación y aceptación de la naturaleza humana y, por consiguiente, la aceptación de la necesidad de Dios.

Como actitud subjetiva, como conciencia de finitud y limitación, la fe empieza por una mera receptividad o pasividad manifestada en la lectura del evangelio que genera un asentimiento de la mente al aceptar la verdad de lo leído, y que culmina en una entrega total a la acción del Creador. Para Lutero no tiene fe aquel que se limita a escuchar la prédica del evangelio, ni siquiera el que lo lee por sus propios medios. Sólo hay una verdadera fe cuando quien accede al evangelio está de acuerdo en que es verdad y se entrega a ello en una rendición incondicional. No se trata por lo tanto de una simple creencia, sino del reconocimiento de la justicia de Dios por parte del ser humano pecador. Fe es sobretodo sinónimo de religión cristiana, es su marca característica, su identidad como parte de la comunidad; su manera particular de ser en el mundo. Así, es más que una simple actitud subjetiva aislada, es lo que distingue y eleva al hombre como un ser con quien Dios se encuentra en una relación especial.

La teología de la fe reemplaza la vieja teología de las obras sobre la base de una negación de la libertad humana, y esto quiere decir que el punto de partida de la nueva doctrina es la absoluta convicción de que la naturaleza humana quedó absolutamente corrompida por el pecado original. Descartada la libertad, las obras carecen de todo fundamento, porque la fe "[...] no es la ilusión humana o el sueño que algunos consideran como tal cuando ven que no sigue un mejoramiento de la vida, ni obras buenas, aunque sin embargo puedan oír y hablar mucho sobre ella, entonces caen en el error y afirman que la fe no es suficiente, de manera que habría que hacer obras para ser bueno y salvo" 33 . Ocurre aquí como cuando algún incauto pretende curar su malestar atacando las consecuencias del mismo, los síntomas, y no las causas que lo producen, porque se trata de corregir la manifestación externa del mal y no su raíz profunda, que sin embargo no depende de él mismo. "Pero la fe es una obra divina en nosotros que nos transforma y nos hace nacer de nuevo en Dios" 34 . Ese don divino establece un contacto directo del ser humano con su creador. Vista de esta forma, la fe en Lutero es algo vivo, activo, poderoso, de manera que es imposible que no produzca el bien permanentemente, que no lleve fuera de sí al hombre elevándolo por sobre su naturaleza pecadora.

Este don, único camino a la salvación, crea en la persona un deseo de permanecer en él, de no volver a su antiguo estado. Es un trabajo constante de unión pasiva con Dios que lo compromete en la acción diaria de su vida, en un progreso constante, en una lucha por asimilar todas las circunstancias mundo-vitales que, en términos de Charles Taylor, constituyen la "afirmación de la vida corriente", la valoración de la existencia cotidiana, escenario secular desde donde se construye, en la labor diaria, la relación con las demás personas en lo que constituye la base de la doctrina de la religiosidad del día laborable, fuente primera del capitalismo según la lectura de Max Weber. La fe es la convicción

32 DUFOUR, Xavier León. Vocabulario de Teología Bíblica. Barcelona: Editorial Herder, 1972.

33 LUTERO, Martín. Comentario a la carta a los Romanos. Volumen I. Traducción de Erich Sexauer. Barcelona: Editorial CLIE, I998, pág. 22.

34 lbídem. 
de tener a Dios como aliado, seguro de su palabra, como voluntad activa que se da al hombre para que éste se le entregue confiado y que permite la elaboración de una cotidianidad consciente en pos del trabajo secular en beneficio de la comunidad, sin la carga moral que exigía la vieja doctrina católica de las obras.

Esa transformación interior que produce en Lutero la nueva concepción de la salvación por la fe o, mejor, esa reforma interior, ese combate para lograr lo más preciado de la vida para el cristiano, y que alcanza una profunda convicción con base en la Escritura, va produciendo la catarsis de ese hombre viejo y acabado dominado por el pecado, para encontrar un hombre nuevo en donde se desarrolla toda la fuerza de la acción de Dios por la fe. Un hombre nuevo que, sin pretenderlo, es el germen de la moderna concepción de la subjetividad humana, subjetividad que es dinamismo y actuación, que es recinto de verdad y constitución del mundo. Porque desde Lutero podemos encontrar en ella el principio fundamental — y existencial— de que todo se resuelve en el fuero de la evidencia interna.

\section{El Reformador reformado}

Hasta el momento hemos tratado de caracterizar, en lo fundamental, el proceso personal de Lutero que lo ha llevado a negar de manera tajante la libertad del hombre. Hemos tratado de describir a grandes rasgos cómo se transforma la concepción de la salvación desde la doctrina de las obras hasta la doctrina de la salvación por la fe. Apoyado principalmente en la Escritura, Lutero se ha ido reformando a sí mismo y ha comprendido, no con poco esfuerzo, que la respuesta a su problema se encuentra en otra parte, en sí mismo, en su contacto con Dios. Esta es tal vez la parte más confusa y paradójica del pensamiento de Lutero, pues en un principio ha dedicado toda su atención y esfuerzo en negar la posibilidad del libre albedrío, pero al final del camino, en la culminación de su proceso de pensamiento, vemos cómo afirma, sin vacilaciones, que la esencia del ser humano es la libertad.

Habíamos dicho al comienzo del texto que la característica que podíamos seguir en este autor era precisamente que llevaba un proceso de elaboración de pensamiento que procedía desde la más profunda crítica de la libertad hasta su más alta aceptación; que desde una negación se elevaba a una afirmación, y que ese proceso que notamos en su obra coincide a su vez con la constitución de la personalidad del autor. En Lutero el resultado final es el ascenso definitivo hacia su personalidad, hacia el hombre que conoce la historia. Solamente podemos hablar de "libertad" en el plano concerniente a la interioridad del ser humano, a su fuero personal e íntimo, a su conciencia, a la certeza subjetiva que alcanza el hombre como un ser que está en una determinada relación con Dios. Después de esta aclaración conviene que nos detengamos un momento a explicar qué es lo que se entiende por personalidad, y por qué nos atrevemos a decir que es este el campo de acción en donde aparece el aporte luterano: el cambio de significación sobre el concepto de libertad que implica enfocar el problema, ya no desde el plano de las acciones humanas, sino de las intenciones, es decir, de la autoconciencia que tiene el sujeto como ser actuante. 
Nuestro ideal de libertad y de sociedad asimismo libre no puede definirse simplemente en términos de independencia. La redención del hombre de hoy significa una libertad que le permita llegar a ser, no un individuo (en su independencia es impotente frente a un Estado gigantesco), sino una persona, capaz de encontrarse a sí misma — en vez de perderse — en la interdependencia de la comunidad ${ }^{35}$.

Partiendo de su concepción dualista del ser humano, entendido como creatura de Dios y en el marco de la cultura cristiana en la que crece, Lutero le adjudica al hombre una dignidad propia por su relación con la divinidad; es un fin en sí mismo y no un medio con miras a otra cosa. Es un ser individual, una persona única, en el sentido que tiene la potencialidad de constituir su identidad desde sí mismo. El concepto de persona es, ante todo, un concepto moral que se desarrolla, que se expresa en la personalidad, en el fluir de su interioridad. Al tener poder sobre sí mismo, sin someterse a la naturaleza dada, elevándose por encima de ella, el ser humano está en la naturaleza, pero no es naturaleza; no se rige por sus leyes sino que, al comprenderlas en su legalidad, las domina al momento de estar en interdependencia con el mundo. Como tal, y Lutero no es ninguna excepción, la personalidad es resultado de una autorrealización: el paulatino control que se va adquiriendo sobre sí mismo. Ese ser a cuya conciencia referida llamamos personalidad, no solamente es consciente de sí mismo, sino de la estructura en la que está inmerso, de la que es parte sin estar sometido a ella. De esta forma, la personalidad se refiere no solo a la capacidad de tener poder sobre uno mismo en un plano interior, por decirlo así, sino a ser capaz de proyectar ese ejercicio de soberanía sobre el mundo exterior. A pesar de lo anterior, eso a lo que llamamos personalidad se afirma y surge como tal sólo en el reconocimiento, en el "enfrentamiento" ante otra conciencia igual. El concepto que tenemos de nosotros mismos se afianza en el contacto con otras personas distintas ante quienes podemos encontrar afinidades, al momento de descubrir también las diferencias que nos alejan de ellas. Es decir, una persona es consciente de sí misma sólo cuando se enfrenta con otros; sólo en esa comunión con el otro aparece el yo, la personalidad actuante que más que un dato es un proceso resultado de una interacción.

En el caso de Lutero encontramos la primera fase de desarrollo de su personalidad "luterana" en el tiempo de su monacato en Erfurt y Wittenberg. Como tal, como parte de la comunidad del monasterio, enmarcado a su vez dentro del complejo universo cultural de la Iglesia Católica, Lutero no podía sino asumir como propias las reglas, las formas de vida y de poder a las que estaba subordinado. En fases de desarrollo personal "primitivas", la comunidad, su espíritu esencial totalizante, trasciende la personalidad del individuo y la domina, la amolda, impidiendo su autodesarrollo ${ }^{36}$. Lutero en el convento no es otra cosa que el ejemplo de lo anterior ${ }^{37}$. Un individuo de por sí temeroso

35 ROBINSON, John A. T. El cuerpo. Estudio de Teología Paulina. Barcelona: Ediciones Ariel, S.A., 1968, pág. I4.

36 FROMM, Erich. El miedo a la Libertad. Buenos Aires: Editorial Paidós, 1982.

37 La versión aprobada comúnmente por la historia de la Reforma sobre la llegada de Lutero al convento de los agustinos no deja de ser en buena parte mítica y plagada de recursos literarios, y también muy cuestionable y llamativa, por el hecho de que se supone que el monacato tiene a la base un hecho decisivo, en que el personaje sufre una angustia y un temor latente por la muerte, es decir, que es de cierta forma un hecho traumático lo que lo conduce hasta su vida religiosa. Más extraño aún si lo 
e inseguro que cree encontrar en su comunidad, en este caso religiosa, la protección y seguridad que necesita para su tranquilidad; sólo como parte de la comunidad, como individuo dentro de ella, alcanza su identidad. El individuo es, por decirlo de alguna manera, un medio y sólo como parte del todo es un fin.

Sin embargo el hecho decisivo en Lutero, que coincide con la evolución de su pensamiento teológico, con la superación de la doctrina de las obras y el advenimiento de la doctrina de la justificación por la fe, es cuando él, como individuo, logra trascender su subordinación, su atadura a la comunidad; Lutero sólo es Lutero cuando logra su autodeterminación consciente, cuando afirma su personalidad al revelarse, al apartarse del seno de la Iglesia y afirmarse a sí mismo, ya no como miembro de una institución, sino como sujeto histórico que comprende el problema de la libertad cristiana. Su personalidad surge por encima y en contra de la estructura de la sociedad jerarquizada, unitaria y cerrada en la que se educa, dando paso al advenimiento posterior de una sociedad individualizada, al trasladar el problema de la justificación desde la intervención de un tercero, al principio de la responsabilidad individual ${ }^{38}$. Esa consolidación de la personalidad implica no solamente un autodesarrollo individual, sino una nueva relación con el contexto circundante. En el caso Lutero es comprensible entonces la reforma posterior de la iglesia; el sometimiento de su realidad social a sus propios fines individuales, que implica también un cambio en su visión de la religión. Estrictamente hablando es desde este punto de vista que se puede entender la influencia del movimiento luterano al interior de la iglesia católica. Si hay algo que provoque la ruptura en la unidad de la iglesia, su división, su proceso de desintegración como poder de cohesión social en el continente europeo, es que el Protestantismo apela, como norma fundamental, a la conciencia individual de las personas, no sólo en cuestiones de fe, sino en su contexto social. El avance de Lutero hacia la consolidación de su personalidad autónoma implica dejar de lado todo un universo de significación colectiva en pos de la consolidación de su vida espiritual. Hemos dicho que es el espíritu, la idea que de sí mismo tiene el grupo, lo que configura la personalidad del individuo en primera instancia; la personalidad, y he tratado de describir la de Lutero, surge solamente por encima y en contra de la estructura social, generando a su vez nuevas formas sociales y culturales — la modernidad — con un sentido diferente al anterior.

La conciencia de la que hablaremos al hacer referencia a Lutero no es la conciencia tal y como la entiende la filosofía, si bien comparte con ella el hecho de considerarla como un elemento exclusivo de la naturaleza humana. Conciencia es un término ético que surge de la más profunda sensación de culpa y se eleva hasta la superación de la moral. Con Lutero nos encontramos a un hombre en conflicto frente a su conciencia moral, un hombre que se comprende a sí mismo como un cristiano, como un ser que se entiende en referencia con el absoluto y que pretende lograr una estrecha relación con él, al alcanzar un estado de unidad y coherencia de su personalidad moral. Esa conciencia

comparamos con otros personajes relacionados con Lutero (San Pablo en el camino de Damasco), y especialmente su antagonista en el medio religioso, San Ignacio de Loyola, quien parece vivir la misma situación de conversión religiosa por su herida en la batalla de Pamplona.

38 FROMM, Erich. El miedo a la Libertad. Buenos Aires: Editorial Paidós, 1982. 
cristiana derivada de la experiencia de la justificación por la fe, que no había sido expuesta en toda su dimensión por otros autores como Pablo y Agustín, deriva en una concepción original:

Una conciencia puede ser llamada «transmoral» si juzga, no en obediencia a una ley moral, sino de acuerdo con la participación en una realidad que trasciende la esfera de los mandatos morales. Una conciencia transmoral no niega el campo de la moral, pero es llevada más allá de él por los conflictos insoportables de la esfera de la ley ${ }^{39}$.

Lutero encuentra esta nueva forma de conciencia en la doctrina de la gracia antes descrita: Dios defiende y salva al hombre de su propia conciencia desesperada por el mal; a pesar de la corrupción moral del hombre que le impide actuar conforme a lo que es debido, Dios se acerca a él y lo acepta tal cual es. Esta idea de la conciencia transmoral en Lutero supone de hecho comunión del hombre con su Creador, unidad con lo universal desde lo individual. La conciencia transmoral en Lutero es, desde esta perspectiva, trascendente, porque acepta el poder de la gracia divina que va más allá de la Ley en el plano de la justificación por la fe. La conciencia del pecado, de la imperfección natural antes citada, llevaba a Lutero a pensar que como ser finito era incapaz de alcanzar lo infinito. ¿Cómo superar entonces esa ambigüedad? Justamente por ella misma. El descubrimiento de Lutero, el de la interioridad de la conciencia que supera las normas morales, la "Ley", le permite descubrir el último paso definitivo hacia su personalidad histórica. Es precisamente de ese sentimiento de vacío, de esa misma ausencia que surge la fe como presencia de lo absoluto en la criatura por su disposición interior.

Lutero puede superar la doctrina que colocaba el problema de la salvación en los actos humanos cuando entiende que Dios no es un juez que castiga apelando a la Ley, sino un ser misericordioso que se proyecta hacia los seres humanos por su amor redentor. Inútil es entonces pretender que un ser omnipotente como Dios tenga que tener en cuenta las acciones humanas y el cumplimiento de las Leyes, como si la relación entre ambos fuera de corte jurídico. En el momento en que percibe ese cambio en la relación con Dios gracias a la lectura del Nuevo Testamento, al comprenderlo como un ser de amor que no le imputa sus pecados y no que lo juzga por sus méritos, Lutero ha logrado alcanzar la paz anhelada. Las obras desaparecen al momento de reconocer que es inútil tratar de cooperar en la propia salvación, que es tiempo perdido tratar de romper la distancia que impone la propia condición humana en la que, como hemos dicho, no se puede hablar de libertad en un sentido tradicional. Contrario a la doctrina católica, Lutero entiende que la justificación de Dios no implica que el pecado desaparezca: Dios suprime la distancia con el hombre, pero no puede cambiar su naturaleza. La salvación deja subsistir el pecado como una huella indeleble de la condición humana, negando de paso el papel de la moral y la acción humanas, básicamente porque la justicia del hombre es incompatible con la justicia de Dios. Por lo tanto el amor de Dios, fuera de toda comprensión humana, no perdona los pecados del hombre, sino que no los imputa ${ }^{40}$. Es este descubrimiento lo

39 TILLICH, Paul. La Era Protestante. Buenos Aires: Editorial Paidós, 1965, pág. 223.

40 ROBINSON, John A. T. El cuerpo. Estudio de Teología Paulina. Barcelona: Ediciones Ariel, S.A., 1968. 
que permite a Lutero dar un paso adelante de la doctrina católica, consolidando el fundamento de su teología que representa, en realidad, una "Revolución total, de una singular audacia. Un momento antes, la actividad furiosa, y vana, del gladiador que hincha sus músculos tan sólo para sucumbir. Ahora, la pasividad total y bendita del resignado que, confesándose vencido antes del combate, no pone ninguna esperanza si no es en el exceso mismo de su derrota"4l.

La salvación proviene de sentir en sí mismo el pecado, pero sobre todo de sentir, por la fe, la presencia de Dios. Esa certeza que se construye gracias a la lectura del texto sagrado, en el fuero de la conciencia individual del creyente, es lo que permite superar la visión de suyo negativa y pesimista que tiene Lutero sobre la naturaleza humana. Descartadas las obras como medios para alcanzar la salvación, se encuentra el creyente solo ante su conciencia, lugar en donde puede hacer presencia la divinidad si se cumple el requisito de renunciar a sí mismo y aceptar la naturaleza salvífica de Dios. La salvación nada tiene que ver con ritos o acciones bien intencionadas, sino que se recibe de Dios de manera completamente pasiva, pues nada puede hacer el hombre para superar su natural condición pecaminosa salvo reconocerla y estar seguro de que Dios no la tomará en cuenta. En el tránsito de la actitud desesperada por actuar bien, propia de sus "tiempos papistas", hacia la actitud serena del hombre maduro que encuentra en la palabra sagrada la promesa de redención, encontramos la personalidad de Lutero. Escuchemos de nuevo al historiador francés: "Va, o más bien salta, de contraste en contraste, brinca con una holgura, una vivacidad, una escalofriante osadía, del pesimismo más desesperado al optimismo más confiado, de una aceptación exaltada del infierno al más dulce abandono en los brazos de la divinidad: del terror al amor, de la muerte a la vida" ${ }^{42}$. De esta forma,

[...] la dialéctica de la reflexión luterana ha conducido a abolir cualquier manifestación o perfil de lo no manifestable, y forzado a tornarse hacia la sombra del hombre interior como espacio en que pueda emerger lo sagrado; pero entonces vuelve a ponerse en movimiento ese anhelo de autenticidad, de desobjetivación, y Lutero debe dibujar la interioridad-fe como una que está vacía y se define solo en términos de la destrucción de la conciencia. Porque, ¿cuál es el contenido y la forma de esta última? Ninguno, sino la auto-negación como conciencia de algo, y la fe, acto que relaciona la subjetividad con lo Infinito, se realiza como purgación y muerte de la conciencia. Así se lleva a cabo la supresión del hombre y la resurrección de lo sagrado ${ }^{43}$.

La interioridad de la conciencia luterana lo es de sí misma por la fe en el amor de Dios, esto es, por la confianza absoluta en la naturaleza redentora del Creador. Por ello debe separarse y abandonar toda comunicación con lo exterior, desvalorizándolo, para abrirse al infinito. La infinitud, dadas estas condiciones, no hallará más asiento que en la subjetividad consciente de sí como subjetividad, no

4I FEBVRE, Lucien. Martín Lutero: un destino. México: Fondo de Cultura Económica, 1998, pág. 58.

42 Ibídem., pág. 63.

43 BALLESTERO, Manuel. La Revolución del Espíritu (Tres pensamientos de libertad). Madrid: Siglo Veintiuno Editores, 1968 , pág. 86. 
en ninguna institución o rito externo como se había concebido hasta entonces. "Esta es la libertad auténticamente espiritual y cristiana: la que libera al corazón de todos los pecados, leyes y preceptos; está por encima de cualquier otra libertad, como lo está el cielo sobre la tierra"44. Según lo anterior, la conciencia humana carece de correlato mundano en pos de la salvación; su único contenido es su intencionalidad, es decir, ella misma, separándose, negando su base material. Sólo de esta forma, enfrentada a ella misma, la conciencia humana alcanza su autonomía y se dispone al encuentro con Dios. Esto es lo que significa conciencia transmoral, la abolición de toda norma y todo contenido de conciencia que tenga una causa externa; una independencia absoluta de toda subordinación a la ley del mundo y un acercamiento profundo sobre la propia interioridad ${ }^{45}$. La fe implica entonces la abolición de esa conciencia dirigida al exterior, la muerte al mundo para que aparezca lo divino y espiritual; la puerta de entrada para la acción salvífica de Dios. Es por lo tanto una libertad interior y espiritual del hombre sobre su propia incapacidad. Ese es el gran descubrimiento y aporte de Lutero que mencionábamos al principio de este escrito: la interioridad humana es la base firme sobre la que se constituirá la autonomía para la salvación, la responsabilidad individual. Entonces se podrá decir, con base en lo anterior, que el hombre debe ser libre por sí mismo al concebir la cercanía de Dios con él, al ubicarlo en el fuero íntimo y personal del hombre concreto y singular. Por ello cada hombre, al superarse a sí mismo, al dejar atrás la coerción del pecado y la ley, se hace libre y responsable de sí por la fe. Hay entonces un proceso de acercamiento del infinito al hombre. Dios, a pesar de su naturaleza esencial como espíritu infinito, cualitativamente diferente de su creatura, se manifiesta en ella por medio de la fe. La libertad del hombre "no consiste en que éste carezca de vinculaciones, ni su individualidad en que deje de ser social. Ambas se derivan de una responsabilidad incondicional e inalienable para con Dios, que no es negada por la solidaridad que el cuerpo comporta, sino que de hecho solo en ella y a través de ella puede ser realizada" 46.

La conciencia humana es, para Lutero, el lugar donde el infinito se manifiesta con total certeza y seguridad, más que como conciencia en sentido teórico. La interioridad de conciencia potencialmente abierta al infinito significa la afirmación de la personalidad de nuestro autor; el superar el nivel de conciencia del mundo significa dejar atrás su vida monacal y en general la doctrina católica de la salvación. Esa interioridad, signo de "madurez" personal en Lutero, necesita carecer de correlato mundano para que pueda estar prisionera de la acción de Dios. Solamente por esta relación del hombre consigo mismo, por esta apertura a lo infinito que parte de su propia negación, se puede llegar a la afirmación de la justificación por la fe. La libertad, por lo tanto, implica la determinación absoluta por medio de un arduo camino de liberación. La libertad cristiana, aunque suene paradójico, se encuentra en lo más profundo de la servidumbre, emergiendo desde lo más profundo del ser humano hasta Dios, así como la semilla emerge desde la oscuridad de la tierra en búsqueda de la luz del sol que la hará germinar a la vida. La justificación es eso en Lutero: renacimiento en la verdad

44 LUTERO, Martin. Obras. Edición de Teófanes Egido. Salamanca: Ediciones Sígueme. 1977, pág. I64. La referencia corresponde a "La Libertad del Cristiano".

45 TILLICH, Paul. La Era Protestante. Buenos Aires: Editorial Paidós, 1965.

46 ROBINSON, John A. T. El cuerpo. Estudio de Teología Paulina. Barcelona: Ediciones Ariel, S.A., 1968, pág. 29. 
y la vida. "Hombre libre es, pues, cristiano o interioridad regenerada que, en su acto, no se refiere más que a sí misma por la fe" 47 .

Alcanzar la justicia de Dios fue el propósito fundamental de la vida de Lutero, y en ese proceso de encontrar su tranquilidad interior contribuyó decisivamente, aunque sin pensarlo, a una transformación epocal. Pero, para finalizar, ¿qué entiende por justicia? Siguiendo a San Pablo, Lutero entiende la palabra justicia como estar en una "debida relación con Dios". Una persona justa es aquella que reconoce su subordinación a lo divino, dejándose conducir por él y haciéndolo evidente en el testimonio de su vida cotidiana. Sin embargo, cuando Lutero nos dice que Dios justifica a un pecador esto no quiere decir que le da la razón por sus acciones y lo acepta como justo, es decir, que aprueba que actúe como lo hace; ni siquiera se refiere a que la justificación implique que Dios hace bueno al pecador. Por el contrario, lo que nos dice Lutero es que Dios "trata al pecador como si no lo fuera". En uno de sus textos de madurez nos dice lo siguiente: "[...] Dios desea tenernos por totalmente justificados a causa de Cristo, nuestro mediador. Aunque el pecado no haya desaparecido del todo ni muerto en la carne, Dios no quiere tenerlo en cuenta ni darse por enterado [...] Lo que aún reste de pecado y de imperfección no será reputado como tal, gracias precisamente a Cristo. El hombre [...] tiene que llamarse, y ser, del todo justificado y santo, en virtud de la pura gracia y de la misericordia, repartidas y derramadas sobre nosotros en Cristo" ${ }^{48}$. Es esta concepción particular de la justicia divina la que genera en Lutero un cambio de perspectiva mucho más consolador a su debate interno, el que le abre la puerta hacia la afirmación de su teología, de su personalidad histórica como hemos venido diciendo. Es el cambio de un paradigma por otro. Dejar de ver a Dios como juez y verlo como padre ${ }^{49}$ es comprenderlo, según Lutero, en su plena dimensión, en su obra característica, en su esencia como ser de amor: "Aunque el pecado no haya desaparecido del todo ni muerto en la carne, Dios no quiere tenerlo en cuenta ni darse por enterado [...] Lo que aún reste de pecado y de imperfección no será imputado como tal, gracias precisamente a Cristo ${ }^{50}$.

Este consuelo que siente Lutero lo lleva a considerar su relación con el pecado de manera diferente: ya no será juzgado por Dios como si fuera un criminal, sino como a un hijo díscolo a quien ama a pesar de todo. Esto es la justificación desde el punto de vista del reformado(r): que Dios considera al pecador como un amigo, como un ser que debe ser amado, más no como trasgresor de la ley que debe ser castigado. Visto así, el problema de la justicia divina tiene solo un camino por recorrer. La única manera posible de llegar a la debida relación con Dios radica en una actitud subjetiva de

47 BALLESTERO, Manuel. La Revolución del Espíritu (Tres pensamientos de libertad). Madrid: Siglo Veintiuno Editores, 1968 , pág. 107.

48 LUTERO, Martin. Obras. Edición de Teófanes Egido. Salamanca: Ediciones Sígueme. 1977, pág. 356. La referencia corresponde a los "Artículos de Schmalkalda".

49 Este asunto de vital importancia es lo que muchos autores de corte psicoanalista (Fromm, Ericsson, Jung) señalan en Lutero como lo más decisivo: su concepción de lo paterno. Del paso de ver a Dios según el modelo de su padre, un minero, un hombre adusto, fiel cumplidor de la ley, implacable en su normatividad, estricto y severo, por la nueva figura paterna que representaba Johanes Von Staupitz, un ser más cercano, amable, cariñoso y comprensivo para con Lutero. Un cambio de visión que se representa como el paso de la visión aterradora del dios del A.T. al Dios del N.T. El cambio de Lutero es, desde esta perspectiva, una nueva valoración de la importancia del N.T. en relación directa con Dios.

50 lbídem. 
confianza absoluta en su palabra. Este único camino es la fe, que no es otra cosa que reconocer, según lo anteriormente dicho, que "[...] la justificación (dikaiosynê) es la relación correcta entre Dios y la criatura humana. El que es justo (díkaios) es el que está en esa correcta relación con Dios —y aquí viene un detalle de suprema importancia-, no por nada que él haya hecho, sino por lo que Dios ha hecho por él'"5l. Por lo tanto ser justificado es entrar en una nueva relación con Dios, una relación directa y sin intermediaciones institucionales, basada en el amor y la confianza, a diferencia de la visión que presenta el Antiguo Testamento en donde la distancia entre Dios y el hombre se administra con la Ley, relación en la que el miedo es la constante. La nueva concepción de la justicia descubierta por Lutero no es la relación con un Dios castigador, sino con uno de perdón y amor redentor. Es decir, el problema de la salvación se explica si se entiende que "la gracia es la mano que da, y la fe, la mano que recibe, como en la famosa pintura de Miguel Ángel"52.

Este es muy a grandes rasgos el proceso vivido por Lutero. Un proceso que lo lleva desde lo más profundo de la desesperación hasta lo más alto de la convicción exige, sin embargo, sacrificar la libertad humana en pos de la salvación del alma. Este proceso es lo que Lucien Febvre llama "el descubrimiento" de Lutero, lo que Manuel Ballestero llama "sujeto trascendental"; lo que Paul Tillich llama "conciencia transmoral". El paso adelante, la concepción teológica que es a la vez una luz personal sobre su alma angustiada. El lograr superar la antigua teología de las obras por la justificación en la fe, el paso de la culpa y el sacrificio físico a la tranquilidad de la conciencia, de un Dios castigador a uno de reconciliación, y a la vez de un hombre viejo a un hombre nuevo, de superar el antiguo sistema de la ley, para sustituirlo con el amor. Esta es una interpretación completamente nueva del mensaje cristiano, una nueva concepción teológica que es el fundamento básico de la Reforma Protestante.

\section{Bibliografía}

ATKINSON, James. Lutero y el nacimiento del Protestantismo. Madrid: Alianza Editorial, 197I.

BALLESTERO, Manuel. La Revolución del Espiritu (Tres pensamientos de libertad). Madrid: Siglo Veintiuno Editores, 1968.

BARCLAY, William. Comentario al Nuevo Testamento. Romanos. Barcelona: Editorial CLIE, 1995.

BENETTI, Santos. Pablo y su mensaje. Buenos Aires: Editorial San Pablo, 1994.

$\mathrm{COHN}$, Norman. En pos del Milenio. Revolucionarios milenaristas y anarquistas místicos de la Edad Media. Madrid: Alianza Editorial, 1985.

DIAZ, Jorge Aurelio ¿Existe el mal moral? En: URIBE BOTERO, Ángela y De GAMBOA TAPIAS, Camila (editoras). Fuentes del mal. Bogotá: Universidad Nacional de Colombia, Universidad del Rosario, 2012.

5I BARCLAY, William. Comentario al Nuevo Testamento. Romanos. Barcelona: Editorial CLIE, 1995, pág. 40.

52 lbídem., pág. 89. 
DELUMEAU, Jean. El miedo en Occidente. (Siglos XIV-XVIII). Una ciudad sitiada. Madrid: Editorial Taurus, 1978.

DUFOUR, Xavier León. Vocabulario de Teología Bíblica. Barcelona: Editorial Herder, 1972.

FEBVRE, Lucien. Martín Lutero: un destino. México: Fondo de Cultura Económica, 1998.

FROMM, Erich. El miedo a la Libertad. Buenos Aires: Editorial Paidós, 1982.

GARCÍA-VILLOSLADA, Ricardo. Raíces Históricas del Luteranismo. Madrid: Biblioteca de Autores Cristianos (BAC), Segunda Edición, 1976.

JARAMILLO VÉLEZ, Rubén. La actitud premoderna y moderna ante la naturaleza. En: Argumentos, número 30. Bogotá: Editorial Argumentos, 1993, págs. 33 - 43.

LUTERO, Martin. Obras. Edición de Teófanes Egido. Salamanca: Ediciones Sígueme. 1977. Escritos Políticos. Edición de Joaquín Abellán. Madrid: Tecnos, 1994. . Comentario a la carta a los Romanos. Volumen I. Traducción de Erich Sexauer. Barcelona: Editorial CLIE, 1998. . De Servo Arbitrio. Traducción de Erich Sexauer. Buenos Aires: Editorial Concordia, 2006.

MARTINEZ, Humberto. Palabras de Martín Lutero. México: Universidad Autónoma Metropolitana, 1984. $\operatorname{tana,} 1985$. Lutero Vs. Erasmo: los orígenes de la secularización. México: Universidad Autónoma Metropoli-

NIPPERDEY, Thomas. Lutero y el mundo moderno. Bogotá: Revista ECO, número 265, año 83, mes II, 1983

OBERMAN, Heiko A. Lutero. Un hombre entre Dios y el diablo. Madrid: Alianza Editorial, 1992.

ROBINSON, John A. T. El cuerpo. Estudio de Teología Paulina. Barcelona: Ediciones Ariel, S.A., 1968.

TAYLOR, Charles. Fuentes del yo. La construcción de la identidad moderna. Barcelona: Ediciones Paidós Ibérica, 1996.

TILLICH, Paul. La Era Protestante. Buenos Aires: Editorial Paidós, 1965.

TROELTSCH, Ernst. El protestantismo y el mundo moderno. México: Fondo de Cultura Económica, 2005. 
